\title{
Tensões entre natureza e sociedade em Diderot e Rousseau ${ }^{1}$
}

Evaldo Becker - Universidade Federal de Sergipe

A amizade de Rousseau com Diderot, que começara em 1742, era bastante cara ao primeiro, e os debates constantes entre eles marcaram inevitavelmente a produção de suas obras. Sobre a confluência de pensamentos e posições que pode ser percebida neste período inicial e sobre o papel de Diderot na concepção do primeiro Discurso, mas também no segundo - apesar de neste as divergências teóricas já serem bastante nítidas -, importa ler o artigo bastante esclarecedor de Antoine Adam, "Rousseau et Diderot", onde o autor apresenta vários pontos de convergência da teoria de ambos, sobretudo no que diz respeito à crítica de um "otimismo rasteiro" (plat optimisme) em relação ao progresso do conhecimento e aos costumes do século XVIII. Tais temas, bem como as tensões entre natureza e sociedade presentes nas teorias

\footnotetext{
${ }^{1}$ Texto redigido no quadro de atividades referentes aos projetos de pesquisa "Rousseau e as Relações Internacionais na Modernidade", financiado pelos editais FAPITEC/SE/FUNTEC/CNPq no 4/2011 e Edital Universal MCTI/CNPq no 14/2012, e "Ética socioambiental em comunidades tradicionais do Baixo São Francisco em Sergipe", financiado pelo Edital de Ciências Humanas, Sociais e Sociais Aplicadas - CNPq, no 18/2012.
} 
de ambos, orientarão nossa exposição.

São muitos os paralelos possíveis de serem identificados nas obras dos dois amigos enciclopedistas. Adam insiste ainda que é Diderot e não Rousseau que na época diz "belezas austeras". Ele cita trechos do verbete "Legislador" da Enciclopédia, no qual Diderot critica o espírito de propriedade ao afirmar que "o legislador deverá transformar o espírito de propriedade em espírito de comunidade", e onde ele louva as leis do Peru por terem estabelecido "a comunidade de bens, enfraquecendo o espírito de propriedade, fonte de todos os vícios" (Adam, 1949, p. 220). Impossível não pensar aqui na célebre crítica desferida por Rousseau na abertura da segunda parte do Discurso sobre a origem $e$ os fundamentos da desigualdade, onde o genebrino atribui ao estabelecimento da propriedade a fonte da desigualdade, de inúmeras guerras, mortes e crimes.

Ambos, Rousseau e Diderot, beberam nos filósofos da tradição republicana o gosto pela vida virtuosa e pelo amor à pátria. Ambos foram leitores de Platão, de Quintiliano, de Cícero. Através de Montesquieu, ou diretamente, leram os exemplos de virtude narrados por Plutarco. Ambos procederam a uma intensa crítica à corrupção dos costumes em voga no século XVIII, e à filosofia intelectualista e otimista da época. Vejamos ainda outra passagem do artigo de Adam no qual este insiste sobre os ideais partilhados pelos amigos enciclopedistas:

A filosofia contemporânea exaltava os triunfos da inteligência, os progressos da razão e das luzes. Para Rousseau, como para Diderot, como para Grimm, a história do homem oferece, ao contrário, o quadro de uma aventura perigosa, que vai contra as intenções da natureza. Eles seguem com bastante atenção os tra- 
balhos de Buffon. Seguindo-o, eles veem no homem primitivo, não o ser razoável (raisonable) que a filosofia havia imaginado, mas um animal de paixões pouco numerosas, que ignora a linguagem e é desprovido de toda vida moral. Essa é a tese do segundo Discurso de Rousseau; é também a tese de Diderot. (Ibid., pp. 22-23)

Ainda no que diz respeito à crítica dos rumos tomados pela civilização e dos abusos que, por vezes, tornam nossa vida em comum mais infeliz do que esta seria no âmbito da natureza pura e sem regras, vivendo de forma independente e livre, Adam menciona duas passagens de artigos da Enciclopédia, a primeira do verbete "Besoin" e a segunda de "Cité". Sobre o primeiro destes, o autor recomenda que

leiamos o artigo de Diderot sobre a necessidade. De início ele segue de perto um capítulo Do espírito das leis. Em seguida, subitamente uma ideia nova aparece: a sociedade, em se desenvolvendo, deu aos homens quiméricas necessidades "que lhes tornam mais infelizes estando unidos do que eles o seriam vivendo dispersos". (Ibid., p. 23)

A segunda passagem é esta: "nós vemos nascer e crescer a corrupção e os vícios com o nascimento e o crescimento das cidades" (Diderot, 2011, p. 119).

Essa mesma postura crítica frente aos pretensos triunfos da razão e da sociedade sobre a natureza são expostos em vários momentos da obra de Diderot. Podemos mencionar aqui o caso do Colóquio de um pai com seus filhos, texto cuja primeira redação se deu em 1771, mas que relata passagens da discussão 
ocorrida por ocasião do último encontro de Diderot com seu pai, em Langres, sua cidade natal, em $1759^{2}$. Nesse conto, o autor escreve:

Nós nos denominamos civilizados, e somos piores que os selvagens. Parece que nos falta ainda girar durante séculos, de extravagâncias em extravagâncias e de erros em erros, para chegarmos lá onde a primeira centelha de julgamento, o instinto sozinho, nos teria levado de um modo totalmente direto. Por isso estamos tão bem extraviados (...). (Id., 2000a, p. 363)

Entretanto, apesar de estarem em aparente acordo acerca dos malefícios provindos do mau uso da razão e do desenvolvimento das sociedades, a partir do momento em que Diderot e Rousseau começam a dar precisão a seus pensamentos, as diferenças vão surgindo, e tornam-se cada vez mais evidentes. No que diz respeito à noção que está na base do pensamento político de ambos, qual seja, o Estado de Natureza anterior à legislação positiva, percebe-se nitidamente a discordância de posições. Para Diderot, esse estado é histórico, e pode ser verificado entre muitos povos selvagens encontrados e descritos por viajantes e naturalistas, ao passo que para Rousseau se trata de um artifício teórico, sem existência histórica. É o que explica Maria das Graças de Souza:

A noção de estado de natureza para Diderot difere essencialmente daquela utilizada tanto por Hobbes quanto por Rousseau. Diderot não coloca a origem da sociedade em termos políticos. Toda a evolução da humanidade está, para ele, inscrita na própria estrutura

${ }^{2}$ Cf. Guinsburg, in Diderot, Obras, II, 2000, p. 346. 
do animal humano. A história da matéria organizada. Assim, pensamento, linguagem e sociabilidade são elementos da natureza humana. O estado de natureza não é, portanto, uma situação hipotética, mas a condição na qual vivem os selvagens da época, e mesmo a condição na qual já viveram todos os povos civilizados. (Souza, 2002, p. 123)

Outra diferença decisiva é a da necessidade ou não de haver contrato, para o estabelecimento do Estado. Essa ideia vai se precisando entre os autores e, em 1752, Diderot publica sua Apologie de M. l'Abbé de Prades, na qual ele declara que desde muito cedo os homens perceberam o interesse de se aproximar. Diderot apresenta ainda a ideia de que os homens no estado de natureza viviam e vivem em bandos (troupeaux $)^{3}$, a exemplo de animais de outras espécies. Diderot remete o leitor à definição hobbesiana de estado de natureza como um estado de desigualdade, violência e medo, regido pela lei do mais forte, em relação ao qual o estabelecimento das leis positivas ocorre como forma de sanar um mal generalizado. Essa ideia é defendida por Diderot (1994b, pp. 538-539), que afirma que os homens se unem naturalmente, em função do medo de serem surpreendidos e mortos pelos demais, e tendo em vista a clara utilidade do estabelecimento de leis e de uma autoridade que possa estabelecer

\footnotetext{
${ }^{3}$ Sobre a noção de estado de rebanho [Troupeau], Diderot explica: "J'entends par l'etat de troupeau celui sous lequel les hommes rapprochés par l'instigation simple de la nature, come les singes, les cerfs, les corneilles, etc. ; n'ont formé aucunes conventions que les assujettissent à des devoirs, ni constitué d'autorité qui contraigne à l'accomplissement des conventions, et où le ressentiment, cette passion que la nature qui veille à la conservation des êtres, a placée dans chaque individu, pour le rendre redoutable à ses semblables, est l'unique frein de l'injustice." (Diderot, 1994, p. 528).
} 
a ordem e garantir as convenções estabelecidas, que transformarão esses "selvagens vagabundos e indisciplinados" em homens policiados. A diferença em relação à concepção de Rousseau não poderia ser mais clara ${ }^{4}$.

O naturalismo político de Diderot se expressará em diferentes escritos de diversos períodos. Mas em que consiste essa doutrina? A essa pergunta responde Maria das Graças de Souza:

Em primeiro lugar, conforme uma perspectiva naturalista, a vida em sociedade é entendida como um instrumento natural que permite aos homens enfrentar com maior facilidade a luta pela sobrevivência e pelo bemestar. A própria instituição da sociedade é natural. O pacto não significa uma ruptura com um estado de natureza, mas decorre da própria natureza. No verbete "soberanos" da Enciclopédia o autor afirma que a luta dos homens contra a natureza é o princípio da sociedade. Impondo aos homens necessidades e expondo-os

\footnotetext{
4"Rousseau découvre entre son ami et lui-même un désaccord grandissant. L'Apologie n'a de sens que s'il existe une 'nature humaine', constante, universelle, une nature définie une fois pour toutes et qui enserre l'homme dans ses déterminations. L'ordre social est nécessaire parce que l'homme est un être passionné et violent, parce qu'il est un loup pour l'homme. Voilà ce que Rousseau refuse d'admettre. Non pas du tout par une sorte d'idyllisme sentimental et naif. Mais parce qu'il n'oublie pas que sur cette notion de l'homme Hobbes a construit la plus réactionnaire des politiques. Et aussi parce qu'il comprend que Diderot, en dépit de ses intentions progressistes, aboutit comme les Morellet et les Turgot à justifier l'inégalité sociale, à sanctionner l'ordre établi et à en masquer les violences. Car si les vices de l'homme appartiennent à la 'nature humaine', quelle raison de lutter pour un ordre meilleur? Mais s'ils appartiennent, comme dit la préface de Narcisse, à 'l'homme mal gouverné', l'œuvre de libération est possible. Le mal n'est plus d'ordre métaphysique, mais politique. L'homme est maître de son destin." (Adam, 1949, pp. 27-28).
} 
constantemente ao perigo, a natureza leva-os a se reunir, "para serem mais felizes". (...) Contra Rousseau, Diderot afirma o instinto natural da sociabilidade, entendendo aqui por instinto o instrumento natural das espécies para garantir a sua conservação. Essa ideia está expressa de modo claro nas Observações sobre o Nakaz, onde, no capítulo LXXII, Diderot escreve que "os homens se reuniram em sociedade por instinto, assim como os animais fracos se reúnem em rebanhos. Certamente não houve, primitivamente, nenhuma espécie de convenção". (Souza, 2002, p. 126)

Esta visão pragmática e utilitarista será criticada por Rousseau em seu Prefácio de Narciso, publicado em 1753. Ali, Rousseau discorda claramente das posturas diderotianas acerca da origem da sociedade expostas na Apologia ${ }^{5}$. Nesta breve obra, que Rousseau considera um de seus bons trabalhos, ele precisa enfaticamente seus próprios pontos de vista, ao afirmar que o interesse não pode fundar a ordem social, "pois para dois homens cujos interesses concordam, talvez cem mil possuem-nos opostos, e não existe outro meio para vencer senão enganar ou perder toda essa gente" (Rousseau, Euvres complètes ${ }^{6}$, III, p. 968).

\footnotetext{
5"Rousseau n'est pas d'accord avec lui (Diderot). A la fin de 1752 il écrit sa préface de Narcisse et cette œuvre brève, mais importante, prend un relief singulier si l'on admet qu'elle vise les quelques pages de l'Apologie où Diderot avait décrit l'origine de la société. Or la préface de Narcisse s'attache à démontrer que l'intérêt ne peut fonder l'ordre social. 'Pour deux hommes dont les intérêts s'accordent, cent mille peut-être le[s] ont opposés'." (Adam, 1949, p. 27).

${ }^{6}$ Doravante OC, acompanhado do volume e página.
} 
A despeito das teorias contemporâneas que legitimavam a situação atual de desigualdade e da exploração, e que argumentavam máximas deterministas apregoando que os vícios verificados em sociedade faziam parte da própria constituição humana, Rousseau irá sustentar, no Prefácio de Narciso, que esses vícios são fruto de uma política injusta, e "não pertencem tanto ao homem, quanto ao homem mal governado" (Rousseau, OC, III, p. 969).

Diderot e Grimm vinham opondo a Rousseau desde 1750 o mesmo tipo de máximas deterministas, que acabavam por aproximá-los das posições dos abades liberais da Sorbonne, tais como Morellet e Turgot. Nesse sentido, Rousseau fora levado a opor a Diderot uma "filosofia da liberdade". O que se evidencia nestes comentários é que "no fim do ano de 1752 Rousseau tem consciência das divergências de pontos de vista que o opõem a seu amigo" (Adam, 1949, p. 28). E é no segundo Discurso que ele irá delinear com mais nitidez sua posição pessoal face as teses da Apologia. Ao fixar o papel do estabelecimento do direito de propriedade como sendo a origem dos malefícios verificados na ordem social, Rousseau se distancia das posturas expostas na Apologia, segundo a qual o direito teria sido criado para proteger os fracos contra os fortes. Ora, conforme o Segundo Discurso, o direito foi criado para sancionar a usurpação dos ricos, e para enfraquecer as reivindicações dos pobres. A oposição destas duas frases, segundo Adam, "fornece exatamente a medida do desacordo onde se encontram o autor da 'Apologia' e o autor do 'Discurso'." (Ibid., p. 29).

Embora nesse momento as posições divergentes se apresentarem de forma clara, isso não significa que os dois amigos tivessem 
percebido nestas divergências motivo para qualquer ruptura ${ }^{7}$. Até porque, como salienta Rousseau nas Confissões, o segundo Discurso foi "a obra que agradou mais a Diderot, mais do que todos os meus outros trabalhos" (Rousseau, OC, I, p. 388). Outra diferença, já presente no segundo Discurso, é a questão de saber se a sociabilidade é ou não natural à espécie humana. Para Diderot, como mostramos acima, a sociabilidade está inscrita na natureza humana, mas, no entender de Rousseau, as causas que levaram o homem ao desenvolvimento da sociabilidade via desenvolvimento da perfectibilidade são contingentes e externas ao homem, e "poderiam nunca ter surgido" deixando-o "eternamente em sua condição primitiva" (Rousseau, OC, III, p. 162).

${ }^{7}$ Adam ressalta que, apesar das divergências verificadas, Rousseau se mostra ainda bastante sensível às sugestões de Diderot, o que poderia ser facilmente verificado se tomarmos o verbete "Economia Política" redigido por Rousseau para a Enciclopédia, no qual se verificam vários traços da influência de Diderot em sua escrita. "N'allons pas pourtant donner à cette opposition un caractère radical que ni Rousseau, ni Diderot n'auraient avoué. L 'Economie Politique, composée par Rousseau dans les mois qui suivirent l'achèvement du second Discours, prouve que son auteur reste encore très sensible aux suggestions de Diderot." (Adam, 1949, p. 29). Ainda sobre os traços da influência diderotiana no verbete "Economia Política", Hubert ressalta a questão da existência de uma sociedade geral do gênero humano ou da "grand ville du monde", que nesta fase Rousseau de certa maneira ainda admitia. Segundo Hubert, "Plus tard, Rousseau deviendra si complètement opposé à l'idée de société générale, que bien loin d'admettre que les besoins mutuels unissent les hommes, il répétera à maintes reprises qu'ils les divisent plutôt qu'ils ne les rapprochent. En fait, à l'époque de l'Economie Politique sa pensée n'est pas encore absolument dégagée de l'influence des encyclopédistes: l'article appartient à une phase de transition, à la dernière des phases de transition, celle où ne retentissent déjà plus que des réminiscences lointaines des opinions des 'philosophes'. Rousseau s'est déjà fâché une première fois avec d'Holbach; il ne va pas tarder beaucoup à rompre avec Grimm et Diderot." (Hubert, 1928, p. 59). 
Se as ideias referentes à noção de sociabilidade natural já se faziam sentir, elas adquirem maior amplitude por ocasião do artigo "Direito Natural" de Diderot, que será foco de uma das principais divergências ocorridas entre os dois amigos. Rousseau irá se contrapor às ideias apresentadas nesse artigo no capítulo II das Instituições Políticas, intitulado "Da sociedade geral do gênero humano", conservado no Manuscrito de Genebra. Esse capítulo, segundo afirma Hubert, configura-se como uma resposta direta à ideia da existência de uma sociedade geral do gênero humano exposta no verbete de Diderot. Hubert confronta grandes passagens do verbete "Direito Natural" e do capítulo "Da sociedade geral do gênero humano", apontando o diálogo empreendido entre os dois autores, onde a diferença de posições é flagrante. Para Hubert, a tese geral de Diderot se desenvolve a partir da ideia de que

a sociabilidade é uma tendência natural - é uma lei da razão, na medida em que ela aspira ao bem comum da espécie inteira; seu princípio deve ser buscado na identidade de natureza de todos os homens; ela é declarada por todos e se exprime nas instituições de todas as sociedades. (Hubert, 1928, pp. 35-36)

Do ponto de vista de Rousseau, entretanto, a expressão "gênero humano" oferece ao espírito apenas uma ideia abstrata e coletiva "que não supõe nenhuma união real entre os indivíduos que a constituem", e o pretenso "tratado social" ditado pela natureza nada mais é do que uma quimera, que não possui existência real (cf. Rousseau, OC, III, p. 284). Tal postura é exposta de maneira precisa na passagem a seguir:

Caso a sociedade geral existisse fora dos sistemas de 
filosofia, representaria, como já afirmei, um ser moral dotado de qualidades próprias e distintas daquelas dos seres que a constituem, mais ou menos como os compostos químicos, que possuem propriedades que não foram tomadas das misturas que os compõem. Haveria uma língua universal que a natureza ensinaria a todos os homens, que seria o primeiro instrumento de sua mútua comunicação, e uma espécie de sensório comum, que serviria à correspondência de todas as partes. (Rousseau, OC, III, p. 284, grifo nosso)

A ausência de uma língua universal, de todo e qualquer sentimento real de pertença que nos ligue indistintamente a todos os seres humanos, aliada à percepção da diversidade evidente dos costumes e da noção de pertença, invalidam ou pelo menos dificultam bastante, para Rousseau, a ideia de uma sociedade geral do gênero humano. Diderot, por outro lado, afirmará, no Plano de uma universidade, que a diversidade das línguas é apenas aparente, e, por serem elas frutos do entendimento, que é o mesmo em todos os homens, suas diferenças são puramente de convenção ${ }^{8}$.

A ausência de qualquer evidência empírica verificável é para Rousseau a dificuldade que a noção de sociabilidade natural nos apresenta. Segundo ele, é somente a partir do estabelecimento das sociedades, que se torna possível o surgimento da moral e

\footnotetext{
8"Seja qual for a variedade aparente que haja entre as línguas, se se examinar o seu objeto de ser, a contrapartida de tudo o que se passa no entendimento humano, perceber-se-á logo que é por toda parte uma mesma máquina submetida a regras gerais, com exceção de algumas diferenças de pura convenção, cujos equivalentes uma língua por gestos encontraria." (Diderot, 2000b, p. 305).
} 
do estabelecimento de leis ${ }^{9}$, que nesse sentido, são gerais com relação à nação à qual pertencemos, mas particulares no que diz respeito às diversas nações. Quanto às leis da natureza, a partir do momento em que nossas paixões se desenvolvem no interior das sociedades particulares, elas se tornam cada vez mais fracas e insuficientes para nos fazerem agir corretamente.

Rousseau insiste que "nós concebemos a ideia de uma sociedade geral a partir de nossas sociedades particulares, e que o estabelecimento das pequenas repúblicas nos faz sonhar com a grande", entretanto, "nós só começamos a nos tornar homens após termos sido cidadãos" (Rousseau, OC, III, p. 287). A intenção de Rousseau, ao escrever o capítulo II do Manuscrito de Genebra, é justamente expressar a necessidade do contrato em contraposição à ideia de uma sociabilidade natural e de um direito anterior à convenção ${ }^{10}$. Mesmo os princípios gerais do

\footnotetext{
9"Como a arte de generalizar suas ideias é um dos exercícios mais difíceis e mais tardios do entendimento humano, o comum dos homens jamais estaria em condições de tirar desta maneira de raciocinar as regras de sua conduta, e quando fosse preciso consultar a vontade geral sobre um ato particular, quantas vezes não aconteceria a um homem bem intencionado de se enganar sobre a regra ou sobre sua aplicação e de seguir suas próprias inclinações pensando estar seguindo a lei? Que fará ele então, para se proteger contra o erro? Escutará sua voz interior? Mas essa voz só se forma, como dissemos, pelo hábito de julgar e sentir no seio da sociedade e segundo suas leis, e não pode então servir para estabelecê-las; além disso, seria preciso que não houvesse crescido em seu coração nenhuma das paixões que falam mais alto que a consciência, cobrindo sua tímida voz, e que fazem sustentar aos filósofos que esta voz não existe." (Rousseau, OC, III, p. 287).

${ }^{10}$ Ao escrever sobre as intenções de Rousseau no capítulo II do Manuscrito de Genebra, Hubert afirma: "Quoiqu'il en soit, la conclusion générale que Rousseau tire de cette longue critique a pour objet d'opposer la doctrine de la nécessité du contrat à la théorie de la sociabilité naturelle ou tout au moins de dénoncer l'insuffisance manifeste de cette dernière." (Hubert, 1928, pp. 48-49).
} 
direito político exprimidos de forma abstrata no Contrato Social devem ser adaptados às situações históricas particulares de cada povo. Como paliativo à ausência de uma sociedade geral, Rousseau sugere que através de novas associações procuremos corrigir a ausência da associação geral ${ }^{11}$.

Os comentadores concordam em afirmar que desde a época em que Rousseau escreve o segundo capítulo das Instituições Políticas ele tem plena consciência do antagonismo que o opõe aos seus companheiros enciclopedistas, e que a longa crítica que ele vem de fazer "tem como objetivo opor a doutrina da necessidade do contrato à teoria da sociabilidade natural ou ao menos denunciar a insuficiência manifesta desta última." (Hubert, 1928, pp. 48-49). Adam (1949, p. 33), após afirmar que entre os referidos autores o diálogo se tornara impossível, acrescenta que este foi o período que marcou o fim de uma das mais fecundas histórias da literatura francesa.

Realmente, no plano teórico, o diálogo se acirrara de tal forma que as posições contrárias se tornaram irreconciliáveis. Mas é bom lembrar que a gota d'água responsável pela ruptura afetiva ocorrida entre Rousseau e Diderot teria sido a publicação da peça $O$ filho natural de Diderot, na qual este afirma que "só o mau vive só", justamente no período em que Rousseau decide se afastar do "teatro de corrupção e de vícios" que ele percebe em

11"Mais, quoiqu'il n'y ait point de société naturelle et générale entre les hommes, quoiqu'ils deviennent malheureux et méchants en devenant sociables, quoique les lois de la justice et de l'égalité ne soient rien pour ceux qui vivent à la fois dans la liberté de l'état de nature et soumis aux besoins de l'état social; loin de penser qu'il n'y ait ni vertu ni bonheur pour nous, et que le ciel nous ait abandonnés sans ressource à la dépravation de l'espèce; efforçons nous de tirer du mal même le remède qui doit guérir. Par de nouvelles associations, corrigeons, s'il se peut, le défaut de l'association générale." (Rousseau, OC, III, p. 288). 
Paris e se isolar em Montmorency, para poder viver e trabalhar de maneira mais simples e prazerosa.

Contudo, apesar da ruptura afetiva, no plano teórico os textos prolongaram o diálogo entre os dois autores. No Suplemento à Viagem de Bougainville, escrito um ano após o aparecimento do relato do próprio Bougainville (1771), mas publicado somente em 1796, Diderot contestará a pretensa superioridade do modelo civilizacional europeu em relação ao "estado de natureza" no qual se encontrariam os selvagens encontrados pelos viajantes do século XVIII e dos séculos anteriores. Neste conto, após afirmar que toda guerra nasce da pretensão comum dos homens civilizados à mesma propriedade ${ }^{12}$, Diderot, através do personagem $B$, que é em certo sentido depositário das posturas do próprio autor, responde à pergunta do personagem $A$, que lhe demanda se ele preferiria o "estado de natureza bruta e selvagem ao estado dito policiado, da seguinte maneira: "Por minha fé, não ousaria declará-lo: mas sei que se viu muitas vezes o homem das cidades despir-se e voltar para a floresta, e que nunca se viu o homem da floresta vestir-se e estabelecer-se na cidade". E, frente à insistência de $A$ que lhe pergunta: "Vejo que, em suma, vos inclinaríeis a julgar os homens tanto mais malvados e infelizes quanto mais civilizados?" $B$ lhe responde em tom que bem poderia ser o de Rousseau: "Não percorri todas as regiões do universo; mas advirto somente que não encontrareis em parte alguma a condição de homem feliz, exceto no Taiti" (Diderot, 2000c, p. 303).

12"Toda guerra nasce de uma pretensão comum à mesma propriedade. $\mathrm{O}$ Homem civilizado tem uma pretensão comum, com o homem civilizado, à posse de um campo de que ambos ocupam as duas extremidades; e esse campo converte-se em motivo de disputa entre eles". (Diderot, 2000c, v. II, p. 271). 
Diderot se serve das descrições dos viajantes para intensificar sua crítica aos costumes franceses e à moral cristã ${ }^{13}$. Em várias passagens do Suplemento, contrapõe a sociedade taitiana, que segue em seu entender a doce e pura lei da natureza, à sociedade europeia que em suas eternas contradições faz com que os homens vivam oprimidos e infelizes. Diderot examina a postura do chefe Ereti, que, num discurso altamente eloquente pronunciado por ocasião da partida das naus dos conquistadores europeus, critica a tentativa de dominação e de corrupção pelos costumes empreendida pelos exploradores. Uma passagem ilustrativa poderia ser esta:

Seguimos aqui o puro instinto da natureza, e tu tentaste expungir de nossas almas seu caráter. Aqui tudo é de todos, e tu nos pregaste não sei que distinção entre o teu e o meu (...). Nós somos livres, e eis que tu fincaste em nosso solo o título de nossa futura escravidão. (...) Nós não conhecíamos senão uma doença, aquela à qual o homem, o animal e a planta foram condenados, a velhice; e tu nos trouxeste outra: infectaste nosso sangue. (Diderot, 2000c, pp. 274-275)

Diderot contrapõe a sociedade taitiana, descrita por Bougainville, como uma sociedade simples, que segue as leis da natureza, às nossas sociedades, caracterizadas como máquinas complexas onde imperam as aparências, os artifícios e as contradições ${ }^{14}$.

13“O Taiti é para Diderot uma anti-Europa, e mais precisamente o contratipo de Europa cristã feudal, modelo de antinatureza." (Varloot, 1972, p. 20).

14" $\mathrm{O}$ taitiano toca a origem do mundo, e o europeu a sua velhice. O intervalo que o separa de nós é maior que a distância entre a criança recém-nascida e o homem decrépito." (Diderot, 2000c, p. 273). 
Conforme Faessel (1996, p. 158), "a exploração filosófica do mito do Taiti retém principalmente dois objetos de reflexão: a oposição entre estado de natureza e o de civilização, e a ideia de felicidade". De fato, tais objetos são centrais na trama do $S u$ plemento. Diderot chega mesmo a atribuir a responsabilidade pelas guerras e pela maioria das mortes ocorridas na humanidade ao estabelecimento das sociedades, numa postura que o colocaria na corrente dos "primitivistas", que advogam em favor do selvagem e contra os malefícios da civilização ${ }^{15}$.

Se, como pudemos perceber, a amizade e o afeto existentes entre Diderot e Rousseau teve fim por volta do ano de 1757, no plano teórico, contudo, suas posições por mais distintas que se apresentem, continuam a se cruzar e a se aproximar em muitos e importantes pontos. A postura exposta acima seria, em nosso entender, plenamente esposada por Rousseau. Além disso, na sequência do texto, Diderot assume outro ponto de vista que já havia sido defendido por Rousseau nos Princípios do direito da guerra, escrito entre os anos de 1756 e 1758 - período-chave no qual se deu a ruptura afetiva entre os dois amigos -, e que faria

\footnotetext{
${ }^{15}$ Respondendo à questão segundo a qual dever-se-ia civilizar os selvagens ou abandoná-los ao seu instinto, Diderot escreve: "Se vós vos propondes a ser seu tirano, civilizai-o; envenenai-o o melhor possível com uma moral contrária à natureza; suscitai-lhe entraves de toda espécie; atrapalhai seus movimentos com mil obstáculos; atribuí-lhe fantasmas que o atemorizem; (...) Quereis vê-lo feliz e livre? Não vos intrometeis em seus assuntos: muitos incidentes imprevistos hão de conduzi-lo à luz e à depravação; e ficai para sempre convencido de que não é por vós, mas por eles, que esses sábios legisladores vos petrificaram e amaneiraram como vós o sois. Invoco o testemunho de todas as instituições políticas, civis e religiosas: examinai-as profundamente; e, ou me engano muito, ou vereis nelas a espécie humana dobrada de século em século ao jugo que um punhado de velhacos decidiu lhe impor. Desconfiai daquele que quer estabelecer a ordem. Ordenar é sempre tornar-se senhor dos outros, incomodando-os." (Ibid., p. 302).
} 
parte do livro II das Instituições Políticas. O ponto em questão, ao qual já fizemos referência, é que o estado de guerra nasce a partir da instituição das sociedades. É algo que Rousseau reitera ao longo de todo o texto, e que aparece de forma clara na seguinte passagem: "Não é senão após ter feito sociedade com algum homem que ele se determina a atacar outro; e ele só se torna soldado após ter-se tornado cidadão". (Rousseau, 2011, p. 159). Essa postura aparecerá de forma nítida no Suplemento, nesta engenhosa analogia criada por Diderot:

Considero os homens não-civilizados uma multidão de molas dispersas e isoladas. Sem dúvida, se porventura algumas dessas molas viessem a chocar-se, uma ou outra ou ambas se quebrariam. Para obviar tal inconveniente, um indivíduo de sabedoria profunda e gênio sublime reuniu essas molas e compôs uma máquina, e nesta máquina denominada sociedade todas as molas foram levadas a ser atuantes, reagindo umas contra as outras, incessantemente fatigadas; e romperam-se mais em um dia, no estado de legislação, do que se romperam em um ano, na anarquia da natureza. Mas que estrépito! Que estrago! Que enorme destruição de pequenas molas, quando duas, três, quatro dessas enormes máquinas vieram a chocar-se com violência! (Diderot, 2000c, p. 303)

O que diferencia fundamentalmente a postura assumida por Diderot no Suplemento daquela de Rousseau, seria justamente o fato de Diderot acreditar na possibilidade de um acesso direto às leis da natureza, e a partir deste ponto, extrair ideias tais como a da existência de uma sociedade geral do gênero humano, 
postura esta que Rousseau considera impossível e mesmo indesejável, dado que as leis são sempre estabelecidas pelos grupos aos quais elas se destinarão, seguindo suas especificidades próprias. Contudo, a crítica das conquistas e espoliações europeias e da violência e desrespeito praticado em suas Colônias, presente no Suplemento e em seus textos para a História das duas Índias ${ }^{16}$ é plenamente compatível com as críticas de Rousseau às guerras de conquista ${ }^{17}$.

A leitura atenta das obras que antecedem e que sucedem a ruptura afetiva de Rousseau e Diderot mostra que, se no plano afetivo a ruptura foi definitiva, no plano teórico eles continuam dialogando. Nesse sentido, estamos de pleno acordo com Adam nesta passagem da qual nos serviremos para encerrarmos nosso texto:

É preciso sempre retornar à questão, tantas vezes tratada, das relações entre Rousseau e Diderot. Não para estudar a história de suas relações pessoais: enquanto não surgirem novos documentos, só poderíamos repetir o que já foi dito, e arriscar hipóteses inverificáveis. Mas, sobre o conflito entre seus respectivos pensamentos, sobre o desacordo doutrinal no qual acaba por chegar um entendimento inicialmente fraternal, a plena luz ainda não foi lançada. (Adam, 1949, p. 21)

${ }^{16}$ Diderot, 1994a, p. 698.

${ }^{17}$ Ver a resposta de Rousseau a Bordes escrita em 1752, na qual o autor escreve: "Afinal, mesmo que todo homem deva ser soldado para a defesa da liberdade, (...) nenhum deve sê-lo para invadir a liberdade do outro" (Rousseau, OC, III, p. 82). 


\section{Referências bibliográficas}

ADAM, A. "Rousseau et Diderot". Revue des Sciences Humaines, Faculté de Lettres de Lille, pp. 21-34, 1949.

BOUGAINVILLE, L.-A. de. Voyage autour du monde : par la frégate la Boudeuse et la flûte l'Étoile. Paris: La Découverte, 1997.

DIDEROT, D. "Cidade". In: Obras, VI. Trad. Newton Cunha e J. Guinsburg. São Paulo: Perspectiva, 2011.

. "Colóquio de um pai com seus filhos: do perigo de colocarse acima das leis". In: Obras, II. Trad. J. Guinsburg. São Paulo: Perspectiva, 2000a.

Histoire des deux indes. In: Euvres, III: Politique.

VERSINI, L. (ed.). Paris: Robert Laffont, 1994a. . Le Neveu de Rameau. Paris: Gallimard, 1972.

___. Plano de uma Universidade. In: Obras, I. Trad. J. Guinsburg. São Paulo: Perspectiva, 2000b. . Suite de l'Apologie de M. L'Abbé de Prades. In: Euvres,

I. VERSINI, L. (ed.). Paris: Robert Laffont, 1994b.

- Suplemento à viagem de Bougainville. In: Obras, II.

Trad. J. Guinsburg. São Paulo: Perspectiva, 2000c.

FAESSEL, S. "Entre l'état de nature et la civilisation : le mythe de Tahiti". Études sur Jean-Jacques Rousseau, Montmorency: Musée Jean-Jacques Rousseau, v. VIII (Rêver Rousseau), pp. 143-160, 1996.

HUBERT, H. Rousseau et l'Encyclopédie: essai sur la formation des idées politiques de Rousseau (1742-1756). Paris: J. Gamber, 1928.

ROUSSEAU, J.-J. As Confissões. Trad. Rachel de Queiroz. São Paulo: Atena Editora, 1936.

. Discurso sobre a origem e os fundamentos da desigual- 
dade entre os homens. Trad. Iracema Gomes Soares e Maria Cristina R. Nagle. Brasília: Ed. UnB, 1989.

Do Contrato Social. In: Rousseau. Trad. Lourdes Santos Machado. São Paulo: Nova Cultural, 1997 (Col. "Os Pensadores").

. Ensaio sobre a origem das linguas. In: Obras escolhidas de J.J. Rousseau, v. II. Trad. Lourdes Santos Machado. Rio de Janeiro: Globo, 1962.

___. Euvres complètes, 5 vols. Paris: Gallimard/ Pléiade, 1964-1995.

. "Princípios do Direito da Guerra". Trad. Evaldo Becker. Transformação, Marília, v. 34, n. 1, pp. 153-171, 2011.

- Projeto de Constituição para a Córsega. In: Obras escolhidas de J. J. Rousseau, v. II. Trad. Lourdes Santos Machado. Rio de Janeiro: Globo, 1962.

SOUZA, M. G. de. Natureza e Ilustração: sobre o materialismo de Diderot. São Paulo: Edunesp, 2002.

VARLOOT, J. "Prefácio" a Diderot, D. Le Neveau de Rameau et autres dialogues philosophiques. Paris: Gallimard, 1972. 